children who show the behavioural disorders but who have never had a fit.

MUREL BLACKBURN
Worthing Road
Horsham RHI2 lJB

\section{Delusional Infestation in Late Life}

SIR: Renvoize et al (Journal, March 1987, 150, 403-405) provide a useful review of the literature, including the German literature, in reporting their interesting patient whose delusions of infestation occurred during the course of a dementing illness. We have been interested to find that delusions of infestation are seen quite commonly among the patients referred to our psychiatric services for the elderly and we recently reviewed seven cases that presented between 1983 and 1986. There were two men and five women. Their ages ranged from 69 to $76-\mathrm{a}$ little above the boundary of 'late middle age', the agegroup from which patients are most frequently reported, but not very old (patients aged 75 and above constitute about three quarters of our referrals).

All seven were found to be depressed. None were seriously demented, although in three there was clear evidence of some organic cerebral impairment and in only one could we be sure that there was no such pathology. In two patients the delusions of infestation developed in the context of guilt at not maintaining cleanliness in the home after the death of a spouse. In three, previous neurotic preoccupation with cleanliness or 'phobia' of 'creepy-crawlies' had become delusional in the setting of severe depression, and in the last two the delusion was part of a systematic belief that the body was changed and degenerating.

In most of our patients the delusions appeared when powerful change of affect occurred with mild organic change. This is a potent combination in the genesis of delusions (Hay et al, 1974). Successful treatment of the mood disorder has led to resolution of the delusions of infestation in the six cases we have known longest. Thus, in this age group delusions of infestation may be less persistent and pernicious than those of the monosymptomatic psychoses that are reported more commonly in younger middle-aged patients. The presence of some organic impairment should not detract from the treatability of the condition through an appreciation of the mood disorder.

Withington Hospital

Michael MorRis

DAVID J. JOLLEY

West Didsbury, Manchester M20 8LR
Reference

HAY, G. G., JOLLEY, D. J. \& JONES, R. G. (1974) A case of the Capgras syndrome in association with pseudo-hypoparathyroidism. Acta Psychiatrica Scandinavica. 50, 73-77.

\section{Hysterical Personality Disorder}

SIR: Thompson \& Goldberg (Journal, February $1987,150,241-245$ ) question the validity, reliability, and utility of the diagnosis of hysterical personality disorder. Though such issues are properly raised about a vexing construct, I believe the authors' gloomy conclusions may not be wholly warranted.

Based on a retrospective review of case notes, Thompson \& Goldberg observe that the diagnosis "is frequently made without the core features being present". Their finding may tell us less about the construct, hysterical personality disorder, than it does about diagnostic practice and documentation at Withington Hospital in 1975. Had the authors tabulated the "core features" present in the case notes of patients with another diagnosis we would be better able to judge where the problem lay.

This matter is of considerable importance because the authors fear that the diagnosis of hysterical personality disorder may be used "to label those patients who are perceived as hostile, difficult, and uncooperative, with the result that the doctor is distracted from recognising an underlying diagnosis". Prominent among such proposed underlying conditions is 'primary affective disorder', which the authors claim that McHugh and I found (Slavney \& McHugh, 1974) in a sample of patients with the diagnosis of hysterical personality disorder. I feel constrained to point out that what we noted was not 'primary' affective disorder, but rather the frequent occurrence of depressed mood and self-injury, phenomena which we interpreted as the responses of self-dramatising and emotionally labile people to stressful circumstances (i.e. as 'secondary' to events such as romantic disappointment). What was 'underlying', then, was the personality disorder, the recognition of which a psychiatrist should not be distracted from by the presence of affective symptoms. The validation of the trait of self-dramatisation has yet to be accomplished, but there is some support (Slavney \& Rich, 1980) for the existence of emotional lability as an actual attribute of patients who receive the diagnosis of hysterical personality disorder.

Finally, the authors observed low inter-rater reliability in the assessment of hysterical traits based on brief videotaped interviews. The diagnosis of personality disorders in the clinical setting, however, depends to a great extent on the description of 
patients by those who know them well, and recent developments in the standardised assessment of traits as rated by informants gives hope that diagnostic reliability can be improved. Using the scale devised by Mann et al (1981), for example, Ballinger (1987) has recently shown acceptable inter-rater reliability in the rating of traits (including hysterical ones) for a sample of patients with mental handicap. As well as this, there is evidence to suggest that judgements about the central trait in the hysterical cluster-self-dramatisation - are not greatly influenced by the sex of the rater or by the sex of the patient (Slavney \& Chase, 1985).

Thompson \& Goldberg call our attention to important matters, but not to lost causes.

- The John Hopkins Medical Institutions

Phillip R. Slavney

600 North Wolfe Street

Baltimore

Maryland 21205

\section{References}

BALLINGER, B. R. (1987) A standardised assessment of personality disorder in mental handicap. British Journal of Psychiatry, 150, 108-109.

Mann, A. H., Jenkins, R., Cuttrng, J. C. \& Cowen, P. J. (1981) The development and use of a standardised assessment of abnormal personality. Psychological Medicine, 11, 839-847.

SLAVNEY, P. R. \& MCHUGH, P. R. (1974) The hysterical personality; a controlled study. Archives of General Psychiatry, 30, 325-329.

\& Rich, G. (1980) Variability of mood and the diagnosis of hysterical personality disorder. British Journal of Psychiatry, 136, 402-404.

- \& Chase, G. A. (1985) Clinical judgements of selfdramatisation; a test of the sexist hypothesis. British Journal of Psychiatry, 146, 614-617.

SIR: Our conclusions are far from gloomy. We draw attention to a group of patients whose response to illness, whether physical or psychiatric, is characterised by difficult, demanding, and aggressive behaviours. Our findings should encourage clinicians to properly examine such patients for underlying illness and not attribute their behaviours and symptoms exclusively to personality disorder. We contend that the recognition of such underlying illnesses in patients affords a greater opportunity for effective treatment than would be the case if they were to be managed simply as 'personality disorders'.

We concede that our data reflects the clinical practices at Withington Hospital, but we have worked in a variety of hospitals in the UK and would describe the practices at Withington Hospital as similar and certainly no worse than those in other hospitals. One author (DG) has also worked in several hospitals in the United States and observes that the particular clinical practices there are comparable. In Slavney \& McHugh's (1974) paper comparing hysterical personality disorder with control patients, the only criteria that referred to the mental state and significantly distinguished between the two groups were the items "dramatic" and "change of therapist". The latter suggests those same behaviours that characterised our index group. Core features such as provocativeness, seductiveness, and lability of mood were not significantly different.

The theme which we consider central is the relative role of illness and personality. The evidence suggests that personality traits may be exagerated by major stress, and that may include an underlying physical or psychiatric illness. The personality disorder simply colours (or sometimes clouds) the presentation as seen by the doctor. To say otherwise ignores evidence amassed from follow-up studies in a variety of hospitals, almost all of which demonstrate a high level of unrecognised illness at the index episode (Slater, 1965; Reed, 1975).

\section{Malham House Day Hospital \\ 25 Hyde Terrace \\ Leeds LS2 6LN}

University Department of Psychiatry

DAVID GOLDBERG

Withington Hospital

Manchester

D. J. THOMPSON

\begin{abstract}
References
REED, J. L. (1975) The diagnosis of hysteria. Psychological Medicine, 5, 13-17.

SLATER, E. (1965) Diagnosis of "Hysteria". British Medical Journal. 1, 1395-1399.

SLAVNEY, P. R. \& MCHUGH, P. R. (1974) The hysterical personality; a controlled study. Archives of General Psychiatry, 30, 325-329.
\end{abstract}

\section{Capgras'Syndrome in a Patient with Dementia}

SIR: I describe a further patient (Kumar, Journal, February 1987, 150, 251), with the additional feature of prominent visual hallucinations.

Case report: An 86-year-old man was referred with a sixmonth history of believing his wife was replaced by an imposter every afternoon-during which time his real wife (78 years old) was soliciting young men in local pubs. At the same time he regularly saw up to four young women in the house. He varied between being annoyed by their intrusion and being friendly towards them when he believed they had come to help with the house-work. On his wife's 'return' he would express anger at her behaviour. After some weeks he began making sexual demands of his wife, stating that he 